\title{
High Solid-Loading Pretreatment/Saccharification Tests with CaCCO (Calcium Capturing by Carbonation) Process for Rice Straw and Domestic Energy Crop, Erianthus arundinaceus
}

(Received August 12, 2013; Accepted October 2, 2013)

(J-STAGE Advance Published Date: October 25, 2013)

\begin{abstract}
Masakazu Ike, ${ }^{1}$ Rui Zhao, ${ }^{1}$ Min-Soo Yun, ${ }^{1}$ Riki Shiroma, ${ }^{1}$ Seiko Ito, ${ }^{1}$ Ying Zhang, ${ }^{1}$ Ying Zhang, ${ }^{1}$ Mitsuhiro Arakane, ${ }^{1}$ Muhammad Imran Al-Haq, ${ }^{1}$ Junko Matsuki, ${ }^{1}$ Jeung-Yil Park, ${ }^{1}$ Mitsuru Gau, ${ }^{2}$ Kenichi Yakushido, ${ }^{3}$ Minoru Nagashima ${ }^{4}$ and Ken Tokuyasu ${ }^{1, *}$
\end{abstract}

\author{
${ }^{1}$ Carbohydrate Laboratory, National Food Research Institute (NFRI), National Agriculture and Food Research Organization (NARO) \\ (2-1-12 Kannondai, Tsukuba 305-8642, Japan) \\ ${ }^{2}$ Forage Crop Breeding Unit, National Agricultural Research Center for Kyushu Okinawa Region, NARO \\ (2421 Suya, Koshi, Kumamoto 861-1192, Japan) \\ ${ }^{3}$ Biomass Research Coordinator, NARO Headquarters, NARO \\ (3-1-1 Kannondai, Tsukuba 305-8517, Japan) \\ ${ }^{4}$ Technical Supervisor, NFRI, NARO \\ (2-1-12 Kannondai, Tsukuba 305-8642, Japan)
}

\begin{abstract}
The CaCCO process (Park et al., 2010), a sugar platform for herbaceous lignocellulosics, was modified and evaluated for fermentable-sugar recovery in solution, using rice straw (RS) as well as stems and leaves of Erianthus arundinaceus (ER), one of the strategic energy crops in Japan. Continuous wet milling of a mixture of feedstock, water and $\mathrm{Ca}(\mathrm{OH})$, with a weight ratio of 3/7/0.3, was adopted, not only to evaluate the applicability for wet feedstocks, but also for simultaneous $\mathrm{Ca}(\mathrm{OH})_{2}$ mixing with the milled feedstocks. We also applied low temperatures of $95-100^{\circ} \mathrm{C}$ for the alkali pretreatment to save energy. Enzymatic-saccharification tests were performed for the pretreatment slurries from $10 \mathrm{~kg}$ feedstocks for $72 \mathrm{~h}$ at $40^{\circ} \mathrm{C}$ under a $\mathrm{CO}_{2}$-pressurized atmosphere at $0.9 \mathrm{MPa}$ with high-solid loadings of $28.4 \%$ (w/w) for RS and $27.8 \%(w / w)$ for ER. These tests successfully solubilized $80.6 \%$ (RS) and $68.1 \%$ (ER) of the total glucose- and xylose residues in the solids. Following centrifugation, the solubilized-sugar concentrations in the recovered solutions were $16.9 \%(w / v)$ for $\mathrm{RS}$ and $15.5 \%(\mathrm{w} / \mathrm{v})$ for ER. Thus, we demonstrated that the CaCCO process could be a simple and flexible platform for preparation of dense sugar solutions from dry- and wet feedstocks, which could stimulate a new agricultural bio-industry for vitalizing rural areas.
\end{abstract}

Key words: calcium-capturing-by-carbonation (CaCCO) process, herbaceous lignocellulosics, rice straw, Erianthus arundinaceus, continuous wet milling

\section{INTRODUCTION}

Fermentable sugars, such as glucose, fructose, sucrose and xylose, are regarded as key compounds in mass-production systems for generating valuable products by the bio-industry; the products include not only simple compounds such as ethanol ${ }^{2)}$ and lactic acid, ${ }^{3)}$ but also larger molecules such as microbial polysaccharides, ${ }^{4)}$ enzymes $^{5)}$ and microbial cells. ${ }^{6}$ ) There is such a great potential for the sugars that it is expected that an inexpensive and stable supply of the sugars in bulk would stimulate a strong bio-industry based on the sugar platform. The supply, however, has heavily depended on molasses, which is unstable due to its variable quality and recovery from individual sugar factories, as well as the increased use for domestic fuel-ethanol production. ${ }^{7)}$ A stable domestic supply

* Corresponding author (Tel. +81-29-838-7189; Fax. +81-29-838-7996; E-mail: tokuyasu@affrc.go.jp).

Abbreviations: $\mathrm{CaCCO}$, calcium capturing by carbonation (Park et al., 2010). ${ }^{1}$ of feedstock is regarded as the central issue for the bio-industry as well as for energy security, and two sources of agricultural products, sugar juice and starch from grains or potatoes, are currently used in large quantities for fuel-ethanol production under the controls required by various governments. The use of agricultural products for fuel-ethanol production would promote domestic agriculture and would thus contribute to food security; however there is concern that it may threaten stable food supplies. ${ }^{8,9)}$

Alternatively, lignocellulosic biomass, which is mainly composed of lignified plant cell walls, has attracted keen interest as a new source of fermentable sugars, because its use would avoid competition with the food supply., ${ }^{89}$ ) Herbaceous biomass in the form of agricultural wastes, such as rice straw, wheat straw, corn stover and sugarcane bagasse, are regarded as promising feedstocks in the framework of current agriculture, because existing systems for their collection, transportation and storage should work to a certain extent. $^{10)}$ In addition, herbaceous energy crops, such as switchgrass, Miscanthus spp. and Erianthus spp., are expect- 
ed to compensate (or substitute) for the agricultural wastes in order to meet the demands of feedstock amounts; biomass yields are typically several times higher yields than agricultural wastes. ${ }^{11)}$ In Japan, Erianthus spp. in the southern to central areas and Miscanthus spp. in the northern areas are regarded as strategic energy crops. ${ }^{11)}$

The supply of fermentable sugars from agricultural wastes and/or energy crops is expected to generate a revolutionary off-the-grid system for new bio-industry in rural areas (http://www.csrees.usda.gov/fo/sustainablebioenergyafri. cfm). In the off-the-grid system, feedstock for the new industries could sustainably gush from fields in rural areas, like the shale-gas revolution that suddenly changed the economies of rural areas by novel horizontal-drilling-/ hydraulic-fracturing technologies. ${ }^{12)}$ If rural agriculture can contribute to this ecosystem by providing a sustainable feedstock supply, it would strengthen the areas with additional labor and markets for the products as well as a better understanding of the pivotal roles of rural agriculture by the community. Furthermore, the versatility of the fermentable sugars would contribute to domestic food- and energy security; they can be used for bioconversion to fuel-ethanol for transportation or to sugars for feeds/foods in case of emergency. ${ }^{13)}$

Herbaceous lignocellulosic biomass generally contains two major polysaccharides: cellulose, a $\beta$-1,4-linked polymer of glucose, and xylan, a $\beta$-1,4-linked polymer of xylose with various side chains. These polysaccharides can be hydrolyzed to give fermentable sugars, glucose and xylose, respectively. They form highly recalcitrant structures with lignin; appropriate pretreatment with the aid of chemical, physical or biological means is necessary prior to hydrolysis to fermentable sugars. ${ }^{14,15)}$ In particular, alkali pretreatment is regarded to be effective since it disrupts linkages of the recalcitrant structures and promotes delignification. ${ }^{14)}$ However, lowering the $\mathrm{pH}$ for alkali recovery and enzymatic saccharification has been a painstaking step after pretreatment; alkalis bind with insoluble lignocellulose making recovery very difficult, and requiring costly acids for $\mathrm{pH}$ control. ${ }^{16,17)}$ Recently, we developed a new alkali pretreatment using lime $(\mathrm{Ca}(\mathrm{OH}) 2)$, "the $\mathrm{CaCCO}$ (calcium capturing by carbonation) process," for enzymatic saccharification of herbaceous biomass. ${ }^{1)}$ The $\mathrm{CaCCO}$ process neutralizes $\mathrm{Ca}(\mathrm{OH}) 2$ with $\mathrm{CO} 2$, converting calcium ions to an insoluble form of $\mathrm{CaCO}_{3}$. It skips solid-liquid separation and washing steps after the pretreatment, so as to entrap solubilized sugars such as sucrose, starch and parts of xylan, as well as reduce water usage. The process is expected to be very effective when fresh rice straw is used as a feedstock, because it may contain significant amounts of starch and sucrose as well as structural polysaccharides in the fibers. ${ }^{18)}$

In this study, we evaluated the $\mathrm{CaCCO}$ process by kg-scale tests for solubilization of fermentable sugars, using rice straw as well as stems and leaves of Erianthus arundinaceus, two of the representative domestic feedstocks that are available in bulk. In laboratory-scale studies, we carried out model experiments with substrates in gram- or milligram quantities, so as to quickly make decisions for process development based on reproducible data. Meanwhile, for the larger-scale tests in this study, we improved the model experiments by substituting more feasible steps using larger and more powerful instruments than those generally found in laboratories, such as a continuous wet-milling machine and a high-pressure saccharification reactor. We also discuss the future prospects for the $\mathrm{CaCCO}$ process as a simple and flexible sugar platform for multiple herbaceous lignocellulosics.

\section{MATERIALS AND METHODS}

Materials. Sun-dried rice straw (RS, Cultivar Koshihikari) was purchased from a domestic farm in Japan in September, 2012. The RS was stored in round bales (dimensions: $1.2 \mathrm{~m}$ (diameter) $\times 1.0 \mathrm{~m}$ (width)) at room temperature. Erianthus arundinaceus (ER) was harvested and collected with a forage harvester (Kemper Champion 3000, Maschinenfabrik KEMPER GmbH \& Co. KG, Stadtlohn, Germany) from an experimental field in Kumamoto, Japan in April, 2012. The ER sample was obtained as chopped pieces of ca. $15 \mathrm{~mm}$ in length, and they were subsequently dried in a greenhouse to a moisture content of less than $10 \%$. The dried samples were then stored in a flexible container at room temperature prior to use.

Component analysis. Samples of RS and ER were further dried at $70^{\circ} \mathrm{C}$ for $3 \mathrm{~d}$. The dried RS sample was cut into ca. $3 \mathrm{~cm}$ lengths with a cutter (Zac-750, Shincowa Co., Ltd., Mishima, Shizuoka, Japan). RS- and ER samples of ca. $1.5^{-3.0} \mathrm{~cm}$ lengths were individually ground with a Willey mill (W-50C, Ikeda Scientific Co., Ltd., Chiyoda, Tokyo, Japan) and passed through a 500- $\mu \mathrm{m}$ mesh sieve. The ground samples were stored in a desiccator at room temperature for component analysis.

The amounts of free glucose, fructose and sucrose in ground samples were measured according to a previously described method. ${ }^{18)}$ Starch and $\beta$-1,3-1,4-glucan were analyzed using a Total Starch Kit and a Mixed-Linkage Beta-Glucan Assay Kit, respectively (Megazyme International Ireland Co., Ltd., Wicklow, Ireland).

The total glucan and xylan contents were determined using a two-step $\mathrm{H}_{2} \mathrm{SO}_{4}$ hydrolysis method. The ground sample (200 mg) was mixed with $1 \mathrm{~mL}$ of $72 \%$ (w/w) $\mathrm{H}_{2} \mathrm{SO} 4$ for hydrolysis at $30^{\circ} \mathrm{C}$ for $1 \mathrm{~h}$. Then, distilled water $(14 \mathrm{~mL})$ was added, and the mixture was further hydrolyzed at $100^{\circ} \mathrm{C}$ for $2 \mathrm{~h}$. The hydrolysate was subjected to centrifugation at $10,000 \times \mathrm{G}$ for $3 \mathrm{~min}$, and the supernatant was recovered for neutralization with $10 \%(\mathrm{w} / \mathrm{v}) \mathrm{NaOH}$. Total glucose and xylose in the neutralized solution were measured using a Glucose C-II Test Kit (Wako Pure Chemical Industries Ltd., Osaka, Japan) and a D-Xylose Assay Kit (Megazyme International Ireland), respectively. The cellulose and xylan contents were calculated from the amount of total glucose and xylose with correction coefficients of 0.9 and 0.88 , respectively.

The amount of acid-soluble lignin was determined by measuring the absorbance of the hydrolysate supernatant at $205 \mathrm{~nm}$ using a value of $105 \mathrm{~L} / \mathrm{g} / \mathrm{cm}$ as the absorptivity of soluble lignin. ${ }^{19)}$ For the quantitative determination of acid-insoluble lignin, the dilute-acid hydrolysis mixture was subjected to centrifugation $\left(8,000 \times \mathrm{G}, 10 \mathrm{~min}, 4^{\circ} \mathrm{C}\right)$ and the supernatant was removed. The precipitate was washed with $5 \mathrm{~mL}$ of water by mixing well with a vortex mixer. The mixed sample was subjected to centrifugation $(8,000 \times \mathrm{G}$, 
$10 \mathrm{~min}, 4^{\circ} \mathrm{C}$ ) and the supernatant was removed. This step for washing the precipitate was repeated five times. The washed precipitate was dried at $105^{\circ} \mathrm{C}$ to constant weight, and then combusted at $600^{\circ} \mathrm{C}$ for $5 \mathrm{~h}$ in a muffle furnace. The remaining ash was weighed as acid-insoluble ash. The amount of acid-insoluble lignin was calculated by subtracting the weight of the acid-insoluble ash from that of the dried precipitate. The total ash contents were estimated by combusting $200 \mathrm{mg}$ of ground powder at $600^{\circ} \mathrm{C}$ for $5 \mathrm{~h}$ in a muffle furnace.

The ester-linked $p$-coumaric acid and ferulic acid contents in the ground samples were determined using a modification of the method of Sun et al. ${ }^{20)}$ : the ground samples $(50 \mathrm{mg})$ were saponified with $5 \mathrm{~mL}$ of $1 \mathrm{M} \mathrm{NaOH}$ solution and $0.5 \mathrm{mg}$ $\mathrm{NaHSO}_{3}$ (to prevent phenolic acid oxidation) in a $15-\mathrm{mL}$ centrifuge tube for $18 \mathrm{~h}$ at $200 \mathrm{rpm}, 30^{\circ} \mathrm{C}$. The sample was subjected to centrifugation at $14,400 \times \mathrm{G}$ for $5 \mathrm{~min}$. The supernatant was then sampled, and the $p$-coumaric acid and ferulic acid contents were determined using ultra-performance liquid chromatography (Acquity TM, Nihon Waters K.K., Tokyo, Japan) equipped with a tunable UV (TUV) detector and a photodiode array (PDA) detector (Nihon Waters K.K.). The separation of $p$-coumaric acid and ferulic acid was performed on an Acquity UPLC BEH C18 column $(2.1 \times 100 \mathrm{~mm}, 1.7 \mu \mathrm{m}$, Nihon Waters K.K.) using a linear gradient consisting of solution $\mathrm{A}(50 \%(\mathrm{v} / \mathrm{v})$ acetonitrile with $0.02 \%$ (v/v) $\left.\mathrm{H}_{2} \mathrm{SO} 4\right)$ and solution $\mathrm{B}(0.08 \mathrm{mM} \mathrm{NaOH})$ over $10 \mathrm{~min}$ from $10 \%$ to $80 \% \mathrm{~A}$ at a flow rate of $0.45 \mathrm{~mL} / \mathrm{min}$ at $40^{\circ} \mathrm{C}$.

Pretreatment. The RS sample was chopped to $10-15 \mathrm{~mm}$ using a shredder (SU-16, Shinkowa Co. Ltd., Japan). The ER sample was already chopped at harvesting, so it was used without further chopping. Each sample (10 kg dry matter) was mixed well with ca. $1 \mathrm{~kg}$ of $\mathrm{Ca}(\mathrm{OH}) 2$ and ca. $23 \mathrm{~L}$ of water in a $100 \mathrm{~L}$ pool, and the mixture was put into a continuous wet-milling machine (Shokusenki, Shinko Engineering Co. Ltd., Japan; Fig. 1). The feed rate of the materials was about $1.5 \mathrm{~kg}$ dry-matter equivalent per hour. The fibrillated sample was put in an autoclave bag (Thermo Fisher Scientific Inc., Pittsburgh, USA), and the bag filled with the milled mixture was heated at $95^{\circ} \mathrm{C}(\mathrm{RS})$ or $100^{\circ} \mathrm{C}$ (ER) for $1 \mathrm{~h}$ in a high-pressure steam sterilizer (KS-323, Tomy Seiko Co.

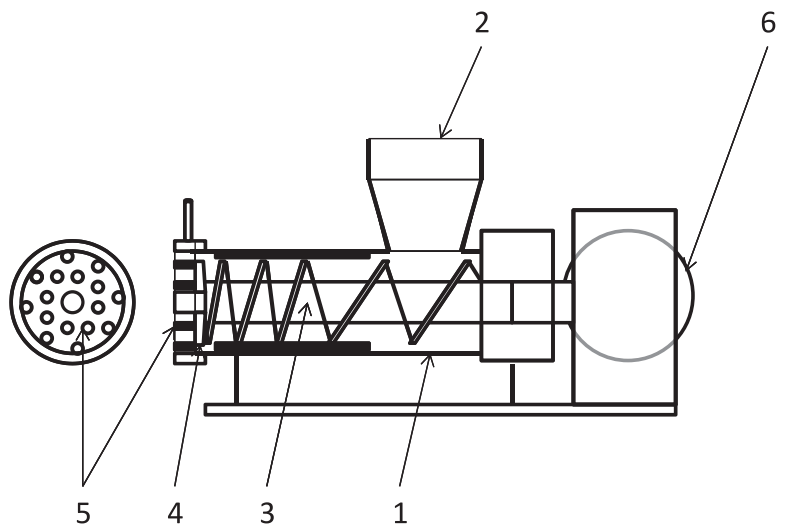

Fig. 1. Configuration of the continuous wet-milling machine (Shokusenki).

1, casing; 2, hopper; 3, screw press; 4, cutter; 5, output disk with pores; 6 , power drive.

Ltd., Tokyo, Japan). The slurry in the bag was then cooled to ambient temperature.

Neutralization and enzymatic saccharification. The neutralization and enzymatic saccharification of the pretreated slurry was carried out in a $\mathrm{CO} 2$-pressurizing saccharification reactor, a semi-tailored, 100-L pressure-resistant reactor with a helical impeller (BMP-100K, coproduction by ABLE \& Biott Co., Ltd., Tokyo, Japan and Tsukasa Industry Co., Ltd., Aichi, Japan, Fig. 2). It was equipped with a circulator attached to the water jacket of the reactor for temperature regulation. The pretreated slurry (ca. 30\% (w/w) of the biomass concentration and ca. $10 \mathrm{~kg}$ of dry biomass) was poured into the reactor, and all valves and caps of the reactor were closed. Then, the valves for $\mathrm{CO}_{2}$ inlet line (V2 and V4, Fig. 2) were opened and $\mathrm{CO}_{2}$ was injected to neutralize the slurry at $0.9 \mathrm{MPa}$ of $p \mathrm{CO}_{2}$ (partial pressure of $\mathrm{CO}_{2}$ ) at $40^{\circ} \mathrm{C}$ overnight with gently mixing (15 rpm). After this neutralization step, enzymatic saccharification was performed using Cellic CTec2 (Novozymes Japan, Chiba, Japan) with a filter paper activity of $165 \mathrm{FPU} / \mathrm{mL}$ at $\mathrm{pH} 5.0$, as measured by the filter paper assay. ${ }^{21)}$ The vent valve (V6, Fig. 2) was opened to reduce pressure in the reactor, and Cellic CTec 2 (12 FPU/g dry feedstock), antifoam and water were added. Then, the reactor was immediately re-pressurized with $\mathrm{CO}_{2}$ up to 0.9 $\mathrm{MPa}$, and kept at $40^{\circ} \mathrm{C}$ for $72 \mathrm{~h}$ with gently mixing (15-30
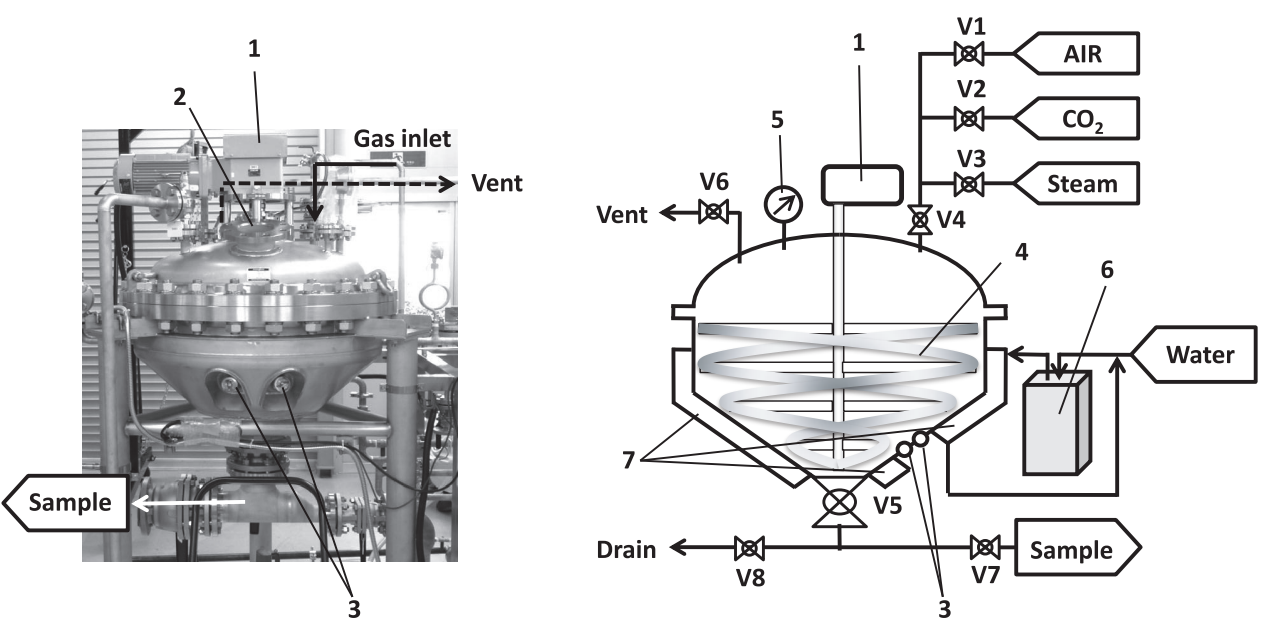

Fig. 2. Configuration of the high-pressure saccharification reactor.

1, motor; 2, sample inlet; 3, sensor ports (temperature, $\mathrm{pH}$ ); 4, helical impeller; 5, pressure indicator; 6, water circulator; 7 , water jacket; V1-8, on-off valves. 
$\mathrm{rpm}$ ). A part of the slurry after saccharification (the saccharification slurry) was separated into the initial liquid fraction (the $1^{\text {st }}$ solution) and the solid fraction by centrifugation at $11,000 \times \mathrm{G}$ at $4^{\circ} \mathrm{C}$ for $30 \mathrm{~min}$. The solids were washed in order to remove residual soluble matter; the solids were re-suspended in distilled water (more than twice the volume of the solid fraction), and the suspension was separated by centrifugation at $11,000 \times \mathrm{G}$ at $4^{\circ} \mathrm{C}$ for $30 \mathrm{~min}$ to obtain solids as the pellet fraction. This step was repeated at least 4 times. The final solid fraction was dried at $65^{\circ} \mathrm{C}$ for $72 \mathrm{~h}$, and was used as the insoluble matter for component analysis. All supernatant fractions in the washing steps as well as the $1^{\text {st }}$ solution were mixed, and the mixture was used as the sugar solution for estimation of fermentable-sugar recovery.

The amounts of glucose and xylose in the sugar solution were determined by using a Glucose C-II Test Kit and D-Xylose Assay Kit, respectively. Each sugar solution was directly used for monosaccharide determination. In addition, the amounts of total glucose- and xylose residues were determined after acid hydrolysis of solubilized sugars in each sugar solution. Briefly, an aliquot of each sugar solution $(500 \mu \mathrm{L})$ was placed in a $2-\mathrm{mL}$ centrifuge tube and subjected to centrifugation at $15,000 \times \mathrm{G}$ for $5 \mathrm{~min}$. The supernatant $(120 \mu \mathrm{L})$ was mixed with $1,080 \mu \mathrm{L}$ of $9 \%$ (w/w) $\mathrm{H}_{2} \mathrm{SO} 4$ solution in a $2-\mathrm{mL}$ screw-capped tube, and the mixture was treated at $100^{\circ} \mathrm{C}$ for $2 \mathrm{~h}$. The amounts of glucose and xylose, including those newly generated by the acid hydrolysis, were measured. The yields of monosaccharides (glucose and xylose) and solubilized sugars [(glucose + glucose-containing oligosaccharides) and (xylose + xylose-containing oligosaccharides)] were calculated according to the following equations:

Monosaccharide yield $(\%)=[$ glucose $($ xylose $)$ amount recovered from saccharification slurry $\times 0.9(0.88)](\mathrm{kg} /$ $\mathrm{kg}$-feedstock)/[glucan (xylan) content in the feedstock] (kg/ kg-feedstock) $\times 100$.

Solubilized-sugar yield $(\%)=[$ glucose $($ xylose $)$ amount after $\mathrm{H}_{2} \mathrm{SO}_{4}$ hydrolysis of the recovered sugar solution $\times 0.9$ (0.88)] (kg/kg-feedstock)/[glucan (xylan) content in the feedstock] $(\mathrm{kg} / \mathrm{kg}$-feedstock $) \times 100$.

\section{RESULTS AND DISCUSSION}

\section{Feedstock evaluation.}

The main components in dry samples of RS and ER are shown in Table 1. We selected the sun-dried RS of Koshihikari, the most widely-grown rice cultivar in Japan. RS may contain significant amounts of readily-recoverable sugars (soft carbohydrates, consisting of sucrose, starch, glucose, fructose and $\beta$-1,3-1,4-glucan). ${ }^{18)}$ Sun-drying of RS is a practically-indispensable step prior to the efficient collection, packaging, transportation and storage, whereas it might significantly decrease the amounts of those soft carbohydrates. ${ }^{18)}$ The data in this study indicate that the soft carbohydrates in the RS sample account for less than 3.3\% $(\mathrm{w} / \mathrm{w})$ of the total dry matter (Table 1$)$.

ER, a perennial crop with an expected recovery of 40-60 $t$ of dry biomass per hectare, contains cellulose and xylan as the main sources of fermentable sugars. ${ }^{11,22)}$ In this study, the ER plant material was chopped with a harvester to give a mixture of ca. $1.5-\mathrm{cm}$ pieces mainly composed of leaves and
Table 1. Major components in dry samples of rice straw and Erianthus arundinaceus used in this study.

\begin{tabular}{|c|c|c|}
\hline \multirow{2}{*}{ Components } & Rice straw & Erianthus arundinaceus \\
\hline & \multicolumn{2}{|c|}{$\%(\mathrm{w} / \mathrm{w} \text { dry matter })^{\mathrm{a}}$} \\
\hline Glucose & $0.09 \pm 0.00$ & $0.60 \pm 0.02$ \\
\hline Fructose & $0.10 \pm 0.00$ & $0.59 \pm 0.02$ \\
\hline Sucrose & $0.11 \pm 0.01$ & $0.31 \pm 0.04$ \\
\hline Starch & $2.40 \pm 0.04$ & $0.10 \pm 0.01$ \\
\hline$\beta-1,3-1,4-$ Glucan & $0.32 \pm 0.01$ & $0.01 \pm 0.01$ \\
\hline Cellulose & $30.5 \pm 0.21$ & $33.0 \pm 0.1$ \\
\hline Xylan & $17.3 \pm 0.62$ & $20.7 \pm 0.1$ \\
\hline$p$-Coumaric acid & $0.63 \pm 0.02$ & $1.78 \pm 0.03$ \\
\hline Ferulic acid & $0.49 \pm 0.01$ & $0.46 \pm 0.01$ \\
\hline Lignin & $15.8 \pm 0.6$ & $25.2 \pm 0.3$ \\
\hline Ash & $18.2 \pm 0.01$ & $5.28 \pm 0.10$ \\
\hline $\mathrm{SCs}^{\mathrm{b}}$ & 3.3 & 1.6 \\
\hline $\mathrm{FSs}^{\mathrm{c}}$ & 56.8 & 61.8 \\
\hline
\end{tabular}

${ }^{a}$ Means \pm standard deviation of triplicate determinations. ${ }^{\mathrm{b}} \mathrm{SCs}$, soft carbohydrates, defined as the sum of glucose, fructose, sucrose, starch and $\beta-1,3-1,4$-glucan in biomass, shown as monomeric-sugar equivalents. ${ }^{\mathrm{C}} \mathrm{FSs}$, fermentable sugars, defined as the sum of SCs, cellulose and xylan in biomass, shown as monomeric-sugar equivalents.

stems. The lignin content of the ER sample was $25.2 \%$, which is 1.6 times more than that of the RS sample; lignin is expected to be a valuable by-product for strengthening the whole bioprocess, although the amount would negatively affect the pretreatment efficiency. ${ }^{2)}$ In contrast, the RS contains 3.4-times more inorganic compounds (18.2\% of total dry matter) than the ER. Ash in the RS is mainly composed of silica, whose industrial use as a by-product would also strengthen the whole process.

Phenolic acids, mainly consisting of $p$-coumaric acid and ferulic acid, are also expected to be valuable by-products from lignocellulosics. Ester-linked phenolic acids are readily hydrolyzed in alkaline conditions, suggesting that they can be recovered in free form after pretreatment in the $\mathrm{CaCCO}$ process. The amounts of the two main phenolic acids differ significantly between feedstocks; the ER sample contains more $p$-coumaric acid than the RS (Table 1). Detailed data of the valuable components in energy crops are very limited, ${ }^{23,24)}$ and integrated studies for mining the potential uses of ER and its related gene resources would greatly accelerate the bioprocess development.

\section{Process design for sugar-solubilization tests in kg-scale.}

Based on our laboratory-scale data, we designed the modified $\mathrm{CaCCO}$ process for the kg-scale sugar-solubilization tests as illustrated in Fig. 3 (A). The sugar solubilization step consists of four main unit steps: (1) wet milling, (2) pretreatment, (3) saccharification and (4) solid/liquid separation-washing. The sugar-solubilization step, our target for evaluation in this study, is the first step of the whole bioprocess (Fig. 3 (B)).

Feedstock milling is regarded as an indispensable step for efficient pretreatment and saccharification by increasing the surface area so as to improve the accessibility by water, chemicals and/or enzymes. The applicability of each milling technique is affected by feedstock properties, final size, and moisture content of the feedstock. ${ }^{25)}$ In this study, we focused on wet fibrillation because we had found in our preliminary experiments that mere fibrillation of feedstock could result in high pretreatment efficiency (data not shown). The other 
A

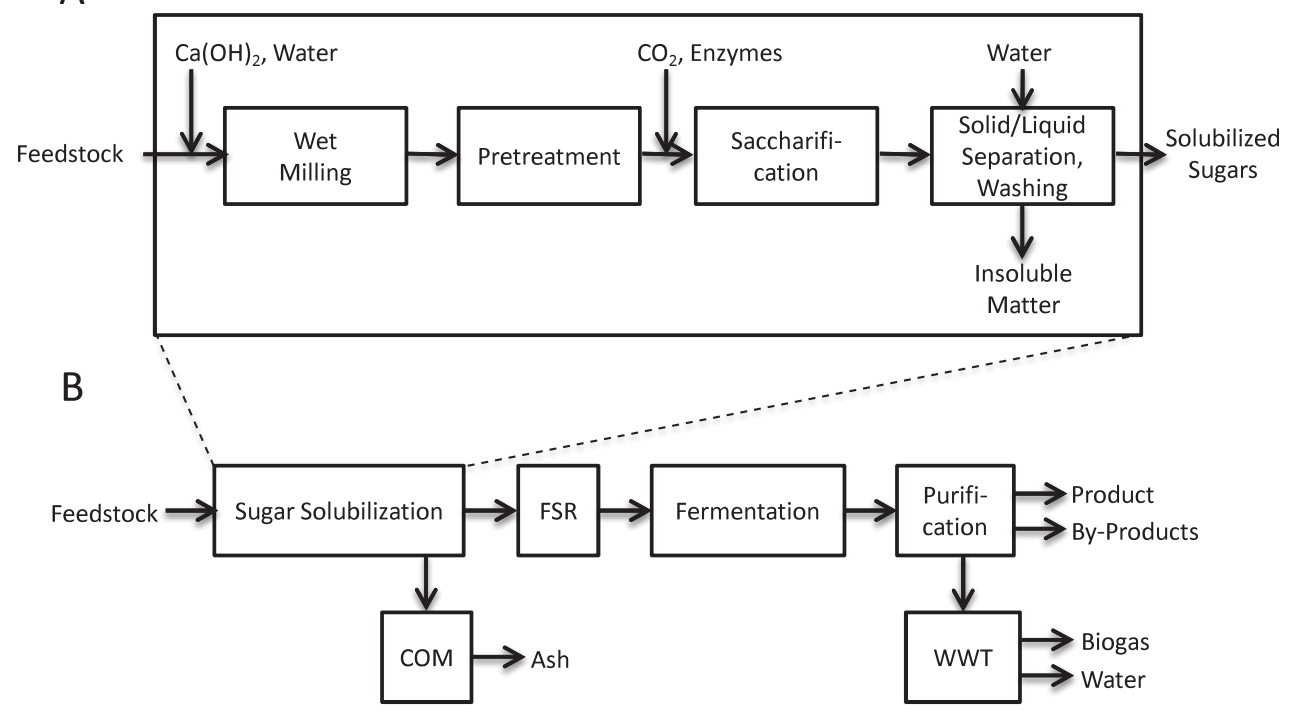

Fig. 3. Flow diagram of the modified $\mathrm{CaCCO}$ process.

(A) Sugar-solubilization step. The feedstock is initially mixed with water and $\mathrm{Ca}(\mathrm{OH}) 2$ and simultaneously milled for fibrillation. The milled feedstock is pretreated at temperatures of $95-100^{\circ} \mathrm{C}$, and enzymatic saccharification is performed under $\mathrm{CO}_{2}$-pressurized conditions. Then, solid/liquid separation and washing of the solid are done to recover solubilized sugars in solution as well as insoluble matter. (B) Whole bioprocess for production of valuables. FSR, fermentable-sugar recovery step; COM, combustion step; WWT, wastewater treatment step. The insoluble matter would go to the COM step for recovery of inorganic compounds and reduction of solid wastes. The solubilized sugars would be transferred to the FSR step; the sugars would be converted to monomeric sugars, the fermentable sugars would be separated with enzymes and/or contaminants, and the sugar solution would be concentrated. Then, fermentation of the sugars would be performed, and the main product as well as by-products would be purified. Finally, wastewater treatment would be performed for the fermentation residues in order to recycle/discharge water and produce biogas.
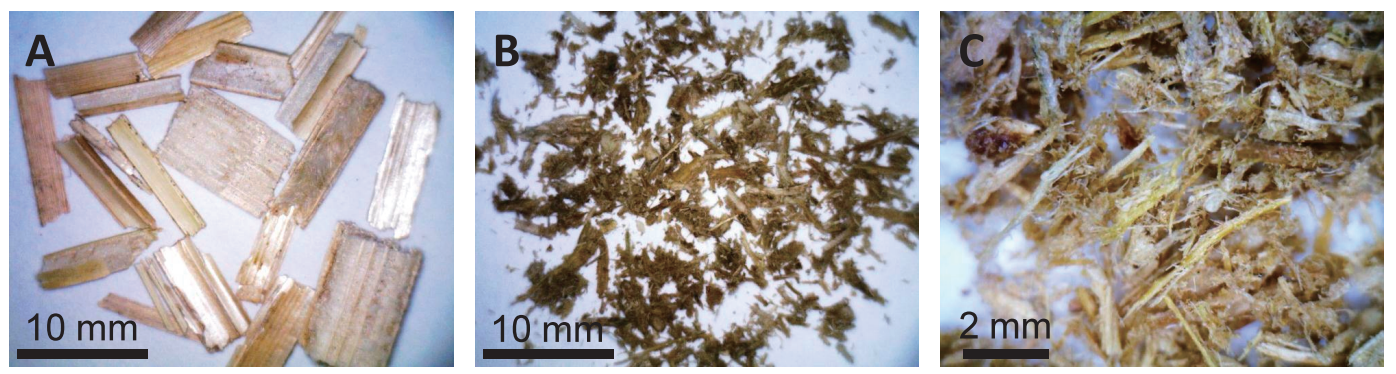

Fig. 4. Appearances of Erianthus feedstock before (A) and after (B and C) wet milling step.

motivation was that bioprocesses starting from wet milling could accept wet feedstocks that are immediately transported in fresh form after harvest. So far, two types of wet milling apparatus, wet disk mills and extruders, have mainly been used for biomass pretreatment. ${ }^{25)}$ Wet disk mills are widely used in industry to reduce the particle size of biomass. Hideno et al. reported its applicability as a continuous and massive treatment of herbaceous biomass. ${ }^{26)}$ Extruders also provide continuous procedures, in which the effect on biomass is disintegration by high shearing force rather than size reduction. In one study, an apparatus equipped with a heater was used for continuous heat pretreatment up to $150^{\circ} \mathrm{C}$ for herbaceous biomass. ${ }^{27)}$ Figure 1 illustrates the continuous wet milling machine used in this study. At a glance the machine appears similar to a simple extruder-like apparatus except for the presence of cutter blades set before the output. This machine swells feedstock fibers by the total effect of shearing forces due to contacts between individual flakes during the feeding, compression, and shearing forces at the cutter near the output. ${ }^{28)}$ Fibrillation of the biomass appeared to be successfully achieved from the chopped feedstock, producing swollen cotton-like material (Fig. 4). In laboratory-scale tests, the effect of wet milling on pretreatment efficiency was comparable to or even better than that of hammer-milled feedstocks, which will be shown in detail elsewhere. In this study, we used the smallest machine with a processing speed of ca. $1.5 \mathrm{~kg}$ dry feedstock/h. We can readily imagine a scenario for scaling the process in future demonstration tests, as the machine company provides several options for larger scale millings; so far the largest machine is reported to have a milling efficiency of 2-3 t dry biomass $/ \mathrm{h}$. In a similar evaluation, pilot-scale lime-pretreatment data for $22.5 \mathrm{~kg}$ of dried wheat straw was reported in 2008. ${ }^{17)}$ Therein, dried wheat straw was ground to pass through a 4-mm screen, and moistened with water. $\mathrm{Ca}(\mathrm{OH}) 2$ solution was then added to the moist flakes, and the slurry was stirred for $24 \mathrm{~h}$. In our study, we attempted a simultaneous mixing of alkali and water with the feedstock during the wet milling step, to allow time for water- and alkalipermeation into the feedstock.

The mixture of feedstock, water and $\mathrm{Ca}(\mathrm{OH}) 2$ was collected in an autoclave bag, and heat pretreatment was performed 
in an autoclave. The temperature of the mixture coming from the output of the mill can be over $70^{\circ} \mathrm{C}$, which could save energy during the heat pretreatment. In our previous study, we set our standard condition for the $\mathrm{CaCCO}$ process for RS at $120^{\circ} \mathrm{C}$ for $1 \mathrm{~h} .{ }^{1)}$ Here we reduced the temperature to $95-100^{\circ} \mathrm{C}$ to save energy, especially that during the phase transition of water at $100^{\circ} \mathrm{C}$. The lower temperature would be favorable for stabilizing $p$-coumaric acid and ferulic acid, which are potential by-products, because both (particularly ferulic acid) are apt to decompose above $100^{\circ} \mathrm{C}$ (data not shown). Also, the adoption of lower temperatures is expected to improve the continuous pretreatment apparatus for demonstration tests by allowing the use of simpler input and output structures. A continuous pretreatment apparatus in the bioethanol bench plant in our institute is now being reconstructed for use with the new pretreatment conditions.

In our previous study, we reported that enzymatic saccharification of the pretreatment slurry under a $\mathrm{CO}_{2}$-atmosphere could be successfully performed. ${ }^{1)}$ Meanwhile, because the cost of enzymes would largely affect the total cost of the product, ${ }^{29)}$ the saccharification step should be further improved to maximize enzyme activities at the optimal $\mathrm{pH}$ as well as minimize the amount of enzymes required. To maximize enzyme activities, we raised the $\mathrm{CO}_{2}$-pressurization by using a high-pressure saccharification reactor in order to further lower the $\mathrm{pH}$ (Fig. 2). The pressurization by $\mathrm{CO}_{2}$ would also cause calcium solubilization by converting $\mathrm{CaCO}_{3}$ to $\mathrm{Ca}\left(\mathrm{HCO}_{3}\right)$; resulting impacts on the saccharification remain to be elucidated. The reactor is also equipped with a powerful helical impeller that is able to mix the slurries at high solid loadings of $28.4 \%(\mathrm{w} / \mathrm{w})$ for RS and $27.8 \%$ (w/w) for ER (Fig. 2). At $0.9 \mathrm{MPa}$ of $p \mathrm{CO} 2$, the $\mathrm{pH}$ in the slurries was approximately 5.7-5.9, which varies depending on feedstocks and/or its concentration. During saccharification the slurries began to show fluidity within $6^{-12} \mathrm{~h}$, and after 72-h dark brown saccharification fluid products were obtained. Leading pretreatment technologies for herbaceous feedstocks often contain post-wash steps for reagent recoveries for reuse and/or removal of potentialinhibitors after pretreatments. ${ }^{30)}$ In contrast, the $\mathrm{CaCCO}$ process was originally designed to entrap water-soluble and/ or solubilized sugars such as sucrose, starch and xylan, which would be washed out during the post-wash step. The simplicity of the modified $\mathrm{CaCCO}$ process could result in a seamless process for sugar solubilization/recovery, with the only output of by-products after the saccharification (Fig. 3 (A)). In this study, a commercially-available cellulase preparation (Cellic CTec2, Novozymes) was solely used at a concentration of $12 \mathrm{FPU} / \mathrm{g}$-dry biomass. Because we focused on solubilization of sugars from solid biomass rather than a single-step monosaccharide-formation, neither $\beta$-glucosidase preparations nor $\beta$-xylosidase preparations were added to the slurries. In future studies we will include an additional post-saccharification step (Fig. 3 (B)) to produce fermentable monosaccharides by enzymatic means. The conversion to monosaccharides would require not only sufficient amounts of glucose- or xylose producing enzymes but also unique enzymes to remove specific residues that prevent monosaccharide formation from specific oligosaccharides. Some enzymes will likely be used in an immobilized form in the post-saccharification process to reduce costs. ${ }^{31)}$

\section{Material balance evaluation.}

Figure 5 illustrates material balance sheets for the modified CaCCO process with RS and ER. After saccharification, the resultant slurries were applied to a solid/liquid separation step for soluble sugar recovery. The solutions obtained after the first centrifugation of saccharification slurries (the $1^{\text {st }}$ solutions), had solubilized sugars at concentrations (shown as monosaccharide equivalents) of $16.9 \%$ for RS and $15.5 \%$ for ER, respectively. The sugar concentrations of the $1^{\text {st }}$ solutions represent those of the whole soluble fraction, including the corresponding solution remaining in the insoluble parts. Therefore, we assumed that the whole soluble fraction could be recovered without any dilution with wash water. Accordingly, the amounts of wash water and wet insoluble-matter were calculated under the assumption that the whole soluble-fraction in the insoluble matter could be recovered by a simple water-exchange with wash water to give a moisture content of $65 \%$ to the insoluble matter.

Starting from $10 \mathrm{~kg}$ of $\mathrm{RS}, 4.6 \mathrm{~kg}$ of solubilized sugars could be obtained with a yield of $80.6 \%$ (glucose equivalent, $77.3 \%$ and xylose equivalent, 86.8\%). The corresponding yield for ER was $68.1 \%$ (glucose equivalent, $59.3 \%$ and xylose equivalent, $82.3 \%$ ), which is significantly lower than that of RS. This difference can be mainly attributed to the low solubilization yield of glucose-equivalents for ER. The value is also much lower than the corresponding data in our preliminary laboratory-scale tests with lower solid loadings up to $5 \%(\mathrm{w} / \mathrm{v})$, whose values for glucose equivalents scored between $73.0-76.5 \%$ (personal communication). Thus, inhibition of cellulolytic enzyme activity in the slurry with a high solid loading could be the main reason for this problem. It is known that high-solid-loading saccharification of lignocellulosic biomass could cause various problems that are not seen in those with low solid loadings. ${ }^{32,33)}$ Among them, neither the reduction of mass-transfer rate nor the high product-sugar concentration are likely to be the central problem in the ER saccharification, because the corresponding data for RS were good. The factors inhibiting cellulolytic activity may be specific to ER; unique compounds in ER could be inhibitors, and well-known inhibitors such as phenolic compounds ${ }^{34)}$ and xylooligosaccharides could play a role. ${ }^{35)}$ Further tests to identify the inhibition mechanisms should be performed in order to optimize the process for ER.

The insoluble matter from RS and ER still contained 2.2 and $2.5 \mathrm{~kg}$ of sugars, respectively, which would be combusted along with residual lignin and other compounds (Fig. 5). The $60-70 \%$ moisture content of the fresh insoluble matter suggests that we cannot expect efficient heat recovery during combustion, but the process should result in a reduction of wastes as well as the recovery of inorganic by-products. Meanwhile, the soluble fraction including solubilized sugars is used for fermentation to generate valuable products. The solution also contains various compounds such as phenolic acids, acetate, fatty acids, calcium ions, lignin fragments and proteins; some could be valuable by-products, and others could inhibit enzyme activities or fermentation.

In the CAFI 3 project, the potential of saccharification slurries was evaluated in terms of ethanol production efficiency, assuming that all of the glucose- and xylose residues in the solubilized sugar fraction can be fermented to 


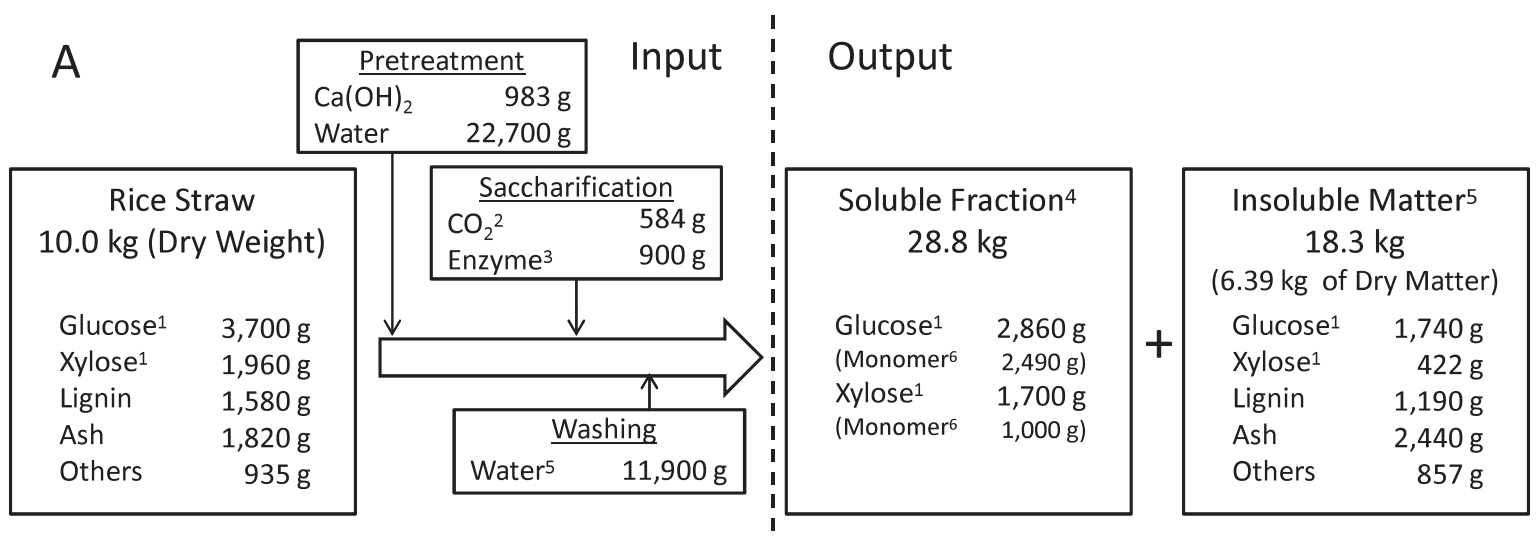

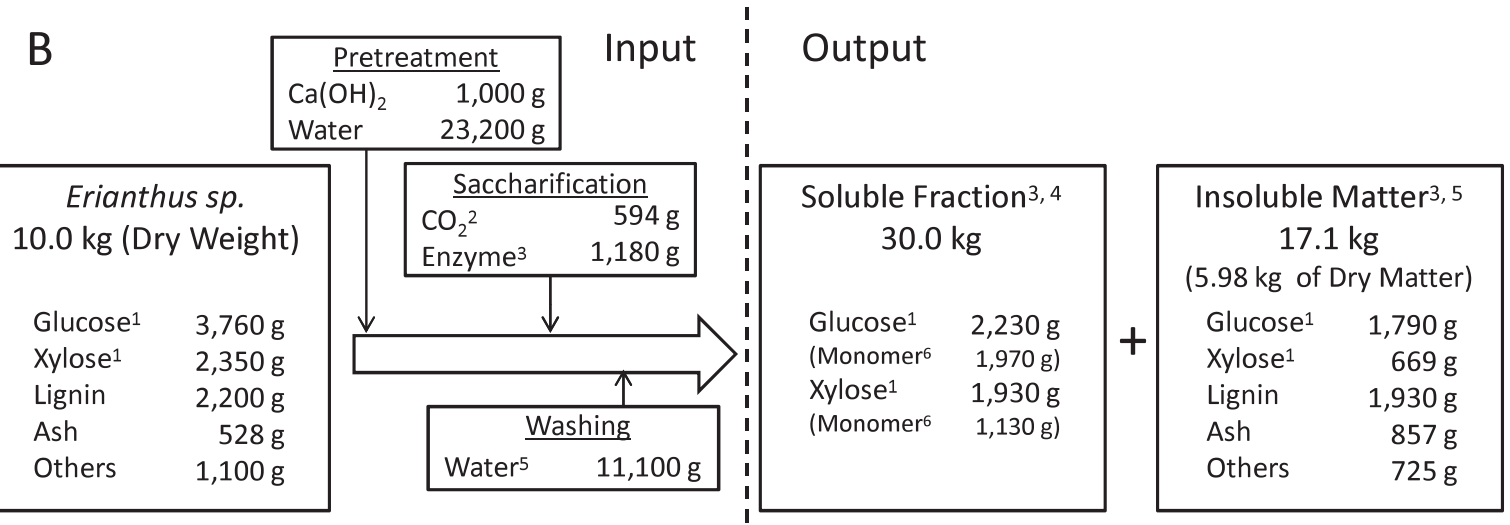

Fig. 5. Material balance for the $\mathrm{CaCCO}$ process using $10 \mathrm{~kg}$ of rice straw (A) and Erianthus arundinaceus (B) as feedstocks.

${ }^{1}$ Total weights of sugars are expressed as monosaccharide equivalent. ${ }^{2}$ The weight of $\mathrm{CO}_{2}$ was calculated by its theoretical amount. ${ }^{3}$ Enzyme solution includes enzymes, antifoam and water, and the total weight of the commercial enzyme preparation accounts for $840 \mathrm{~g}$. ${ }^{4}$ The weight of soluble fraction was calculated assuming that all water and water-soluble matter in saccharification slurry could be recovered in the fraction. ${ }^{5}$ The weight of water was calculated by its theoretical amount to give moisture content of $65 \%$ to insoluble matter. ${ }^{6}$ The weight of corresponding monosaccharide existing in the saccharification solution before acid hydrolysis is shown.

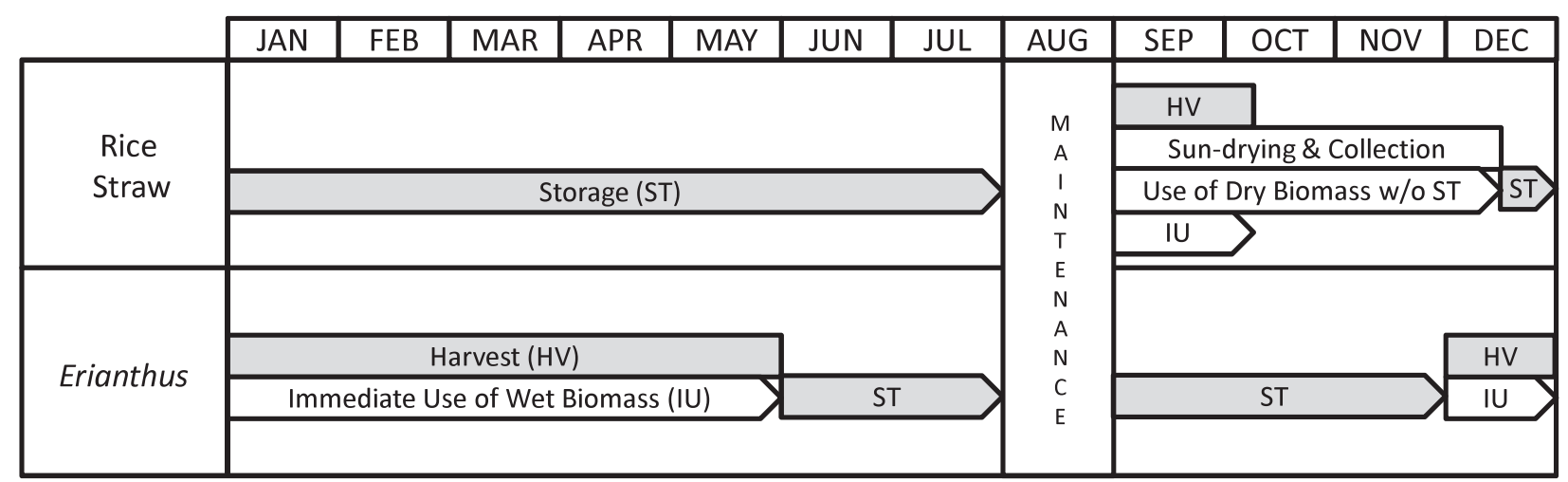

Fig. 6. The proposed model schedules for one-year feedstock supply of rice straw and/or Erianthus arundinaceus.

ethanol with yields of $92 \%$ for glucose and $85 \%$ for xylose, respectively. ${ }^{36)}$ When we simply apply the test-calculation method for our saccharification solutions in Fig. 5, the ethanol yields from RS and ER should reach $263 \mathrm{~mL} / \mathrm{kg}$ dry feedstock and $239 \mathrm{~mL} / \mathrm{kg}$ dry feedstock, respectively. However, these are optimistic values because such efficient technologies for fermentation and monosaccharide recovery have yet to be industrialized, as mentioned by the authors. ${ }^{36}$ )

In this study, we demonstrated that the modified $\mathrm{CaCCO}$ process can accept two strategic feedstocks: RS and ER. This process would provide a flexible sugar-production platform by using multiple feedstocks; it would significantly strengthen the bioprocess by providing stable and long-term feedstock supplies as well as a risk-hedge for the shortage of one feedstock. Model schedules for a one-year supply of RS and/or ER in central Japan are shown in Fig. 6. In this model, rice grains are harvested in a very short period from September to early October. The simultaneously-generated RS is laid on the field and sun-dried for at least several days between autumn and early winter. Dried RS is readily roll-baled for transportation and storage, and some bales are immediately used for conversion to eliminate the need for storage. When RS is regarded as the sole feedstock for the bioprocess, a very large storage area would be needed for the large numbers of bales required for long-term use from mid-December to July.

Meanwhile, ER can be harvested in a long period from December to the end of May in wet form with various 
moisture contents. As in sugar mills that accept dailyharvested raw sugarcane-stalks, our new wet milling $\mathrm{CaCCO}$ process could use daily-harvested raw ER as feedstock (IU, Fig. 6). The process could significantly reduce the cost of ER storage, spread out the harvesting, transportation and storage labor over a longer period, and maintain the quality of the feedstock by avoiding decomposition during storage. If ER is regarded as the sole feedstock, storage for only 5 months should be considered. Furthermore, when RS and ER are used in an ideal combination, only a 2-month stock of feedstock would be needed for use from June to July (Fig. 6). Thus, both the flexibility of the process and the acceptance of wet feedstocks would significantly improve the feasibility of rural sugar platforms with individual combinations of feedstocks.

In conclusion, the modified $\mathrm{CaCCO}$ process would provide a novel sugar platform for solubilized-sugar production with the aid of rural agriculture. The current bench scale plant developed in this study is estimated to process as little as $330 \mathrm{~kg}$ solubilized sugars/y. The simplicity and flexibility of our process is expected to lead to several demonstration tests on larger scales for various fermentation products, which will greatly facilitate the evolution of the process. We expect that the process will contribute to the vitalization of rural bio-industry via production of valuable products from fermentable sugars abundantly and sustainably available from the fields in rural areas.

\section{ACKNOWLEDGMENTS}

We are grateful to M. Tabuse, H. Nakayama, M. Miyamoto, A. Kimura, K. Yamanaka, M. Fujimoto, X.F. Lv, Y. Miyamoto, M. Ikumo, X.J. Geng and Y. Nishiguchi for excellent technical assistant. This work was supported by a grant from the Ministry of Agriculture, Forestry, and Fisheries of Japan (Rural Biofuel Research Project).

\section{REFERENCES}

1 ) J.Y. Park, R. Shiroma, M.I. Al-Haq, Y. Zhang, M. Ike, Y. AraiSanoh, A. Ida, M. Kondo and K. Tokuyasu: A novel lime pretreatment for subsequent bioethanol production from rice straw: Calcium capturing by carbonation $(\mathrm{CaCCO})$ process. Bioresour. Technol., 101, 6805-6811 (2010).

2 ) L. Wu, M. Arakane, M. Ike, M. Wada, T. Takai, M. Gau and K. Tokuyasu: Low temperature alkali pretreatment for improving enzymatic digestibility of sweet sorghum bagasse for ethanol production. Bioresour. Technol., 102, 4793-4799 (2011).

3 ) K. Saito, Y. Hasa and H. Abe: Production of lactic acid from xylose and wheat straw by Rhizopus oryzae. J. Biosci. Bioeng., 114, 166-169 (2012).

4 ) T.D. Leathers and S.C. Gupta: Production of pullulan from fuel ethanol byproducts by Aureobasidium sp. straw NRRL Y-12974. Biotechnol. Lett., 16, 1163-1166 (1994).

5 ) M. Ike, J.Y. Park, M. Tabuse and K. Tokuyasu: Cellulase production on glucose-based media by the UV-irradiated mutants of Trichoderma reesei. Appl. Microbiol. Biotechnol., 87, 2059-2066 (2010).

$6)$ Z. Zhang, S. Srichuwong, T. Kobayashi, M. Arakane, J.Y. Park and $\mathrm{K}$. Tokuyasu: Bioconversion of L-arabinose and other carbohydrates from plant cell walls to $\alpha$-glucan by a soil bacterium, Sporosarcina sp. N52. Bioresour. Technol., 101, 9734-9741 (2010).

7 ) V.T. Hanh, L. T-B. Phuong and L.T. Hung: Sustainable ethanol production in Vietnam: Current status and proposed solutions. in $8^{\text {th }}$ Biomas-Asia Workshop, Hanoi, Vietnam, (2011). http://www. biomass-asia-workshop.jp/biomassws/08workshop/abstract.html

8 ) B. Hahn-Hägerdal, M. Galbe, M.F. Gorwa-Grauslund, G. Lidén and G. Zacchi: Bio-ethanol - the fuel of tomorrow from the residues of today. Trends Biotechnol., 24, 549-556 (2006).

9 ) M.A. Carriquiry, X. Du and G.R. Timilsina: Second generation biofuels: Economics and policies. Energy Policy, 39, 4222-4234 (2011).

10) H. Kato, G. Kanai, Y. Kobayashi, K. Takekura and K. Yakushido: Study on a rice straw collection model using the system dynamics method. Jpn. J. Farm Work Res., 46, 179-187 (2011). (in Japanese)

11) T. Hattori and S. Morita: Energy crops for sustainable bioethanol production; which, where and How? Plant Prod. Sci., 13, 221234 (2010).

12) J.M. Barth: The economic impact of shale gas development on state and local economies: benefits, cost, and uncertainties. New Solut., 23, 85-101 (2013).

13) T. Hayashi: Effects of biofuel introduction and their evaluation method. in Quantitative Evaluation of Effects of Biofuel Introduction, Environmental Project Data \#1, Policy Research Institute, the Ministry of Agriculture, Forestry and Fisheries, Japan. ed., Arai Press, Tokyo, pp. 1-23 (2009). (in Japanese)

14) Y. Sun and J. Cheng: Hydrolysis of lignocellulosic materials for ethanol production: a review. Bioresour. Technol., 83, 1-11 (2002).

15) M.E. Himmel, S.Y. Ding, D.K. Johnson, W.S. Adney, M.R. Nimlos, J.W. Brady and T.D. Foust: Biomass recalcitrance. Engineering plants and enzymes for biofuels production. Science, 315, 804-807 (2007).

16) V.S. Chang, M. Nagwani and M.T. Holtzapple: Lime pretreatment of crop residues bagasse and wheat straw. Appl. Biochem. Biotechnol., 74, 135-159 (1998).

17) R.H. Maas, R.R. Bakker, A.R. Boersma, I. Bisschops, J.R. Pels, E.D. Jong, R.A. Weusthuis and H. Reith: Pilot-scale conversion of lime-treated wheat straw into bioethanol: quality assessment of bioethanol and valorization of side streams by anaerobic digestion and combustion. Biotechnol. Biofuels, 1, 1-14 (2008).

18) J.Y. Park, T. Seyama, R. Shiroma, M. Ike, S. Srichuwong, S. Nagata, K. Sanoh, M. Kondo and K. Tokuyasu: Efficient recovery of glucose and fructose via enzymatic saccharification of rice straw with soft carbohydrates. Biosci. Biotechnol. Biochem., 73, 1072-1077 (2009).

19) M. Taniguchi, M. Tanaka, R. Matsuno and T. Kamikubo: Evaluation of pretreatment for enzymatic solubilization of rice straw. Eur. J. Appl. Microbiol. Biotechnol., 14, 35-39 (1982).

20) R.C. Sun, X.F. Sun and S.H. Zhang: Quantitative determination of hydroxycinnamic acids in wheat, rice, rye, and barley straws, maize stems, oil palm frond fiber, and fast-growing poplar wood. J. Agric. Food Chem., 49, 5122-5129 (2001).

21) T.K. Ghose: Measurement of cellulase activities. Pure Appl. Chem., 24, 257-268 (1987).

22) P. Mislevy, F.G. Martin, M.B. Adjei and J.D. Miller: Harvest management on quantity and quality of Erianthus plant morphological components. Biomass Bioener., 13, 51-58 (1997).

23) M. Yamamura, S. Noda, T. Hattori, A. Shino, J. Kikuchi, K. Takabe, S. Tagane, M. Gau, N. Uwatoko, M. Mii, S. Suzuki, D. Shibata and T. Umezawa: Characterization of lignocellulose of Erianthus arundinaceus in relation to enzymatic saccharification efficiency. Plant Biotechnol., 30, 25-35 (2013).

24) Z. Hu, R. Sykes, M.F. Davis, E.C. Brummer and A.J. Ragauskas: Chemical profiles of switchgrass. Bioresour. Technol., 101, 32533257 (2010).

25) L. Kratky and T. Jirout: Biomass size reduction machines for enhancing biogas production. Chem. Eng. Technol., 34, 391-399 (2011).

26) A. Hideno, H. Inoue, K. Tsukahara, S. Fujimoto, T. Minowa, S. Inoue, T. Endo and S. Sawayama: Wet disk milling pretreatment without sulfuric acid for enzymatic hydrolysis of rice straw. Bioresour. Technol., 100, 2706-2711 (2009).

27) C. Karumanithy and K. Muthukumarappan: Effect of extruder parameters and moisture content of switchgrass, prairie cord 
grass on sugar recovery from enzymatic hydrolysis. Appl. Biochem. Biotechnol., 162, 1785-1803 (2010).

28) K. Hirata: Biomass utilization by Shokusenki. Kensetsu no Sekoukikaku, (Jap. Construct. Machinery Construct. Assoc.), 667, 27-31 (2005). (in Japanese)

29) D. Humbird, R. Davis, L. Tao, C. Kinchin, D. Hsu, A. Aden, P. Schoen, J. Lukas, B. Olthof, M. Worley, D. Sexton and D. Dudgeon: Process design and economics for biochemical conversion of lignocellulosic biomass to ethanol, in Technical Report, NREL/TP-5100-47764, pp. 40-43 (2011).

30) R.J. Garlock, V. Balan, B.E. Dale, V.R. Pallapolu, Y.Y. Lee, Y.M. Kim, N.S. Mosier, M.R. Ladisch, M.T. Holtzapple, M. Falls, R. Sierra-Ramirez, J. Shi, M.A. Ebrik, T. Redmond, B. Yang, C.E. Wyman, B.S. Donohoe, T.B. Vinzant, R.T. Elander, B. Hames, S. Thomas and R.E. Warner: Comparative material balances around pretreatment technologies for the conversion of switchgrass to soluble sugar. Bioresour. Technol., 102, 11063-11071 (2011).

31) M. Tu, X. Zhang, A. Kurabi, N. Gilkes, W. Mabee and J. Saddler: Immobilization of $\beta$-glucosidase on Eupergit $C$ for lignocellulosic hydrolysis. Biotechnol. Lett., 28, 151-156 (2006).
32) J.B. Kristensen, C. Felby and H. Jørgensen: Yield-determining factors in high-solids enzymatic hydrolysis of lignocellulose. Biotechnol. Biofuel., 2, 11. doi: 10.1186/1754-6834-2-11 (2009).

33) D.B. Hodge, M. Nazmul Karim, D.J. Schell and J.D. McMillan: Soluble and insoluble solids contributions to high-solids enzymatic hydrolysis of lignocellulose. Bioresour. Technol., 99, 89408948 (2009).

34) E. Ximenesa, Y. Kim, N. Mosier, B. Dien and M. Ladisch: Inhibition of cellulases by phenols. Enzyme Microb. Technol., 46, 170176 (2010).

35) Q. Qing, B. Yang and C.E. Wyman: Xylooligomers are strong inhibitors of cellulose hydrolysis by enzymes. Bioresour. Technol., 101, 9624-9630 (2010).

36) L. Tao, A. Aden, R.T. Elander, V.R. Pallapolu, Y.Y. Lee, R.J. Garlock, V. Balan, B.E. Dale, Y. Kim, N.S. Mosier, M.R. Ladisch, M. Falls, M.T. Holtzapple, R. Sierra, J. Shi, M.A. Ebrik, T. Redmond, B. Yang, C.E. Wyman, B. Hames, S. Thomas and R.E. Warner: Process and technoeconomic analysis of leading pretreatment technologies for lignocellulosic ethanol production using switchgrass. Bioresour. Technol., 102, 11105-11114 (2011). 